\title{
OPTIMIZED HIGH-PERFORMANCE LIQUID CHROMATOGRAPHY-FLUORESCENCE DETECTION METHOD FOR THE MEASUREMENT OF GLYCINE, PROLINE, AND HYDROXYPROLINE CONCENTRATIONS IN PORCINE GELATIN
}

\author{
ARYATY EKASARY, HARMITA*, BAITHA PALANGGATAN MAGGADANI \\ Department of Pharmacy, Faculty of Pharmacy, Universitas Indonesia, Depok 16424, Indonesia. Email: igakadeharmita@gmail.com \\ Received: 03 June 2018, Revised and Accepted: 21 November 2018
}

\section{ABSTRACT}

Objective: The aim of this study is to develop an optimized method for glycine, proline, and hydroxyproline content quantitation in porcine skin gelatin.

Methods: Gelatin was isolated from porcine skin by hydrolysis for $24 \mathrm{~h}$ in $0.5 \mathrm{M}$ acetic acid, heating in distilled water at $55^{\circ} \mathrm{C}$ for $3 \mathrm{~h}$, and drying at $60^{\circ} \mathrm{C}$. The extract was evaluated by organoleptic tests, Fourier-transform infrared spectroscopy, moisture assay, ash assay, and viscosity test. Gelatin amino acids were derivatized using 9-fluorenylmethylchloroformate-chloride and measured by high-performance liquid chromatography (HPLC) with fluorescence detection using a C18 column after the optimization of the mobile phase composition, flow rate, and detection wavelengths.

Results: The optimized parameters for the quantitation of glycine, proline, and hydroxyproline by HPLC with fluorescence detection were as follows: Excitation wavelength, $265 \mathrm{~nm}$; emission wavelength, $320 \mathrm{~nm}$; mobile phase composition acetic buffer: acetonitrile, 55:45; and flow rate, $0.8 \mathrm{~mL} / \mathrm{min}$. The average proportional amino acid contents were $28.57 \pm 0.74 \%, 19.24 \pm 0.48 \%$, and $2.89 \pm 0.33 \%$ for glycine, proline, and hydroxyproline, respectively.

Conclusion: This method allows for sensitive and accurate quantitation of glycine, proline, and hydroxyproline in porcine skin gelatin samples for quality control and source determination.

Keywords: Derivatization, Fluorenylmethoxycarbonyl chloride, Glycine, High-performance liquid chromatography, Hydroxyproline, Optimization, Porcine gelatin, Proline.

(c) 2018 The Authors. Published by Innovare Academic Sciences Pvt Ltd. This is an open access article under the CC BY license (http://creativecommons. org/licenses/by/4. 0/) DOI: http://dx.doi.org/10.22159/ijap.2018.v10s1.72

\section{INTRODUCTION}

Gelatin is a valuable protein source derived from collagen denaturation. Gelatin production is currently increasing to meet the growing market demand [1]. On the basis of the data from the Indonesian Central Statistics Agency (2014), gelatin production increased substantially from 2010 to 2014. The leading source of gelatin globally is porcine skin (46\%), followed by cow skin (29.4\%) and cow bone (23.1\%), and all other sources account for only $1.5 \%$. The predominance of porcine as a gelatin source is attributed to the low price and shorter manufacturing times [2].

The isolation of gelatin from porcine skin is easier and faster using the acidic method than alkaline extraction from skin or cow bone. Production of B-type gelatin from both cow skin and bone requires prolonged pretreatment with lime and water at ambient temperature, and the subsequent calcification process takes approximately 5-20 weeks (usually 8-12 weeks) depending on the previous treatment. In contrast, after acid treatment, porcine skin is ready for extraction with hot water [3].

The parameters used to characterize gelatin for commercial distribution include $\mathrm{pH}$, organoleptic features, water content, ash content, viscosity, and functional group analysis using Fourier-transform infrared (FTIR) spectroscopy. The amino acid composition of gelatin differs depending on the source (animal tissue) but always contains large quantities of glycine, proline, and hydroxyproline. Therefore, the determination of amino acid content in gelatin can be used to determine the source of gelatin. Indeed, this is the basis for the analyses used to verify the source of gelatin in circulation.
Several studies have been conducted on the amino acid contents of gelatin. In several studies, quantitation was based on derivatization using the 6-aminoquinolyl-N-hydroxysuccinimidyl carbamate reagent $[4,5]$. Alternatively, Fabiani et al. conducted an amino acid analysis of fruit juice using 9-fluorenylmethoxycarbonyl chloride (FMOC-Cl) for derivatization, followed by high-performance liquid chromatography (HPLC) [6]. Analysis of glycine, proline, and hydroxyproline was preceded by hydrolysis to produce amino acid fragments, and the resulting amino acids were further derivatized in pre-columns using FMOC-Cl to form fluorescent compounds for detection. The use of FMOC-Cl can provide good analytical results with high sensitivity and has also been used for the analysis of amino acids in porcine gelatin using HPLC with fluorescence detection [7-10].

The aim of this study was to optimize the conditions for quantitation of glycine, proline, and hydroxyproline in porcine gelatin using FMOC-Cl derivatization and HPLC with fluorescence detection.

\section{MATERIALS AND METHODS}

\section{Materials and reagents}

Porcine skin was purchased from the Central Depok II market. Standard porcine gelatin was obtained from Sigma-Aldrich. Other materials (and suppliers) included FMOC-Cl (Hangzhou Dingyan); L-hydroxyproline, L-proline, and glycine (Sigma-Aldrich); Aquabidest (PT Ikapharmindo putramas); $\mathrm{HCl}$ (Merck); NaOH (Merck); boric acid (Merck); HPLCgrade acetonitrile (Merck); HPLC-grade methanol (Merck); and glacial acetic acid (Merck).

HPLC

The HPLC system (LC 20AT, Shimadzu) was connected to a YMCTriart ${ }^{\circledR}$ C18 column and fluorescence detector (Shimadzu FTIR-8400S 
equipped with DRS-800 and Shimadzu ultraviolet-visible [UV-Vis]-1601 Spectrophotometer). Samples were injected manually using a KCKT syringe (SGE).

\section{Method}

\section{Gelatin extraction}

Porcine skin was cleaned of hair and flesh in water and cut into small pieces $(\approx 2 \mathrm{~cm} \times 2 \mathrm{~cm})$. Skin samples were first pretreated with $4 \% \mathrm{v} / \mathrm{v} 0.5 \mathrm{M}$ acetic acid for $24 \mathrm{~h}$. After neutralizing to $\mathrm{pH} 6$ by washing with water, the skin samples were weighed and treated with hot $\left(55^{\circ} \mathrm{C}\right)$ water for $3 \mathrm{~h}$. The soluble gelatin was separated from the skin fragments using filter paper. The gelatin extract was then concentrated and dried at $60^{\circ} \mathrm{C}$ for $24-36 \mathrm{~h}$ until the formation of a solid sheet. The gelatin sheet was wrapped in plastic and vacuum stored in a desiccator [11].

\section{Organoleptic and physicochemical characterization}

The organoleptic properties of gelatin were evaluated based on the Indonesian National Standard (SNI) 01-3735-1995. The gelatin produced from porcine skin was observed for the color of the solid form and the color in solution. The gelatin samples extracted as described were compared to standard gelatin prepared in the same way. Briefly, extracted and standard gelatin samples were prepared for analysis by mixing $2 \mathrm{mg}$ with $100 \mathrm{mg} \mathrm{KBr}$ in a mortar and grinding to homogeneity. The suspension was transferred into a cup until full, left to solidify, and then analyzed by FTIR.

The $\mathrm{pH}$ measurements were performed according to the Gelatin Manufacturers Institute of America (GMIA) standard method (2013). A 1.5-g gelatin sample was dissolved in $100 \mathrm{~mL}$ of water at $45^{\circ} \mathrm{C}$. The solution was cooled to room temperature, and the $\mathrm{pH}$ was measured using a standard $\mathrm{pH}$ meter.

The moisture content was measured according to GMIA standards (2013). A $1 \mathrm{~g}$ sample of gelatin powder was placed in an open container, weighed, heated at $110^{\circ} \mathrm{C}$, and cooled in a desiccator. This process was repeated until the total weight of the sample and container was constant. The weight decrease was calculated as the $\%$ moisture content.

Measurement of ash content was conducted according to GMIA standards (2013). Gelatin powder (1 g) was inserted in a previously weighed porcelain cup. The cup was placed in a high-temperature furnace at $600^{\circ} \mathrm{C}$ and then cooled in a desiccator. This process was repeated until the total weight of the cup and sample was stable. The ash content was calculated as the residue weight.

Viscosity was measured by the GMIA method (2013). A 6.67\% gelatin solution was prepared and tested at $60^{\circ} \mathrm{C}$ using an Ostwald viscometer with the appropriate spindle and three-speed variations. Viscosity values were calculated in millipoise (mps).

\section{Determination of optimal analysis conditions}

Optimization of gelatin hydrolysis for fluorophore labeling

Approximately $50 \mathrm{mg}$ of standard porcine gelatin was mixed with $5 \mathrm{~mL}$ of $6 \mathrm{~N} \mathrm{HCl}$ and heated at $110^{\circ} \mathrm{C}$ for 22,23 , or $24 \mathrm{~h}$. After cooling, the hydrolyzed samples were dissolved in distilled water to homogeneity, yielding three $1000 \mu \mathrm{g} / \mathrm{mL}$ gelatin solutions. The optimal hydrolysis time was determined by comparing scan rate optima.

Determination of optimum detection wavelengths

A standard solution containing $10 \mu \mathrm{g} / \mathrm{mL}(0.076 \mathrm{mM})$ each of hydroxyproline, glycine, and proline was mixed with $300 \mu \mathrm{L}$ of FMOC-Cl derivatization solution. Samples were tested using UV-Vis spectrophotometry to obtain the maximum lambda excitation and optimization of emission wavelengths following HPLC separation under controlled analysis conditions. Wavelengths were selected according to the largest scan rate optima.
Selection of optimal mobile phase composition

A standard solution of porcine gelatin was derivatized as described and injected into the HPLC system (up to $20 \mathrm{~mL}$ ) for separation using an isocratic mobile phase of $50 \mathrm{mM}$ acetate buffer: acetonitrile at a ratio $55: 45,60: 40$, or $65: 35$. The optimum mobile phase ratio was chosen based on the separation between two adjacent peaks or resolution (R), peak sharpness, tailing factor (Tf), retention time of peak discharge, and column efficiency (number of theoretical plates [N] and height equivalent to the theoretical plate [HETP]).

\section{Selection of optimal flow rate}

A standard solution of porcine gelatin was derivatized and injected into the HPLC system (up to $20 \mathrm{~mL}$ ) and separated using the optimal mobile phase composition (determined as described above) flowing at $0.8,1.0$, or $1.2 \mathrm{~mL} / \mathrm{min}$. The optimal flow rate was selected based on $\mathrm{R}$, peak sharpness, Tf, retention time of the peak, $\mathrm{N}$, and HETP.

\section{Conformance testing}

The derivatized porcine gelatin sample $(20 \mu \mathrm{L})$ was injected into the HPLC system 6 times under optimized separation and detection conditions and the coefficient of variation were recorded for $\mathrm{R}$, peak sharpness, Tf, retention time, $\mathrm{N}$, and HETP.

Construction of the calibration curve, linearity testing, and determination of the limit of detection (LOD) and limit of quantitation (LOQ)

Aqueous standard solutions of each amino acid were prepared at 1 , $2,4,5,10$, and $20 \mu \mathrm{g} / \mathrm{mL}$ and derivatized as described for the sample preparation. Each solution was injected (up to $20 \mu \mathrm{L}$ ) into the HPLC system under optimized separation and detection conditions. The LOD and LOQ were derived from the linear regression plot.

Determination of amino acid levels in gelatin samples from porcine skin A 50-mg sample of extracted gelatin from porcine skin was mixed with $5 \mathrm{~mL}$ of $6 \mathrm{~N} \mathrm{HCl}$ and incubated in an oven at $110^{\circ} \mathrm{C}$ for 22, 23, or $24 \mathrm{~h}$. After cooling, the sample was dissolved in $50 \mathrm{~mL}$ distilled water to obtain a standard solution of $1000 \mu \mathrm{g} / \mathrm{mL}$. The sample was homogenized and derivatized as described and then injected into the HPLC system (up to $20 \mu \mathrm{L}$ ) under optimized separation and detection conditions. Each sample was analyzed in triplicate.

\section{RESULTS AND DISCUSSION}

\section{Porcine gelatin isolation}

The porcine skin gelatin analyzed in this study was categorized as Type A as it was isolated using an acid solution. According to Ward (1977), acid is able to convert the triple helix collagen fibers into single chains, an appropriate form of extraction. This process also results in skin tissue swelling, which can remove unwanted materials such as fat and non-collagen proteins. In this study, porcine skin was soaked in acid solution for $24 \mathrm{~h}$ and washed with running water until the $\mathrm{pH}$ was neutral $(\sim 6)$ because, in general, $\mathrm{pH}$ near the isoelectric points of non-collagen proteins facilitates coagulation and separation. Collagen from the neutralized skin was extracted with distilled water $(600 \mathrm{~mL})$ by heating to $55^{\circ} \mathrm{C}$ for $3 \mathrm{~h}$. Extraction with warm water will continue the destruction of crosslinks as well as weaken the collagen-stabilizing hydrogen bonds. The gelatin solution obtained from the extraction was then filtered and dried for $36 \mathrm{~h}$ in thin layers at $60^{\circ} \mathrm{C}$, a temperature that will not denature the polypeptide chains. After forming a dry thin layer on a vapor plate, the gelatin was cooled in a desiccator. The average yield obtained from this gelatin extraction process was $8.99 \%$.

\section{Gelatin characteristic identification}

\section{Organoleptic observation}

The resulting porcine gelatin did not have the distinctive, brownishyellow color of standard porcine gelatin.

\section{Purity determination by FTIR}

The typical gelatin FTIR spectrum was divided into four parts. The signal at $3600-2300 \mathrm{~cm}^{-1}$ indicates a strain of the amide group bond $(\mathrm{N}-\mathrm{H})$ 
associated with the hydrogen bond. The wide peak shape indicates the presence of hydroxyproline $\mathrm{OH}$ groups. Amide I at 1661-1636 $\mathrm{cm}^{-1}$ shows a $\mathrm{C}=\mathrm{O}$ strain, $\mathrm{N}-\mathrm{H}$ bending, $\mathrm{C}-\mathrm{N}$ strain, and the $\mathrm{OH}$ group paired with a carboxyl group.

The absorption zone at $1650-1660 \mathrm{~cm}^{-1}$ is known as the absorbent region of the imide residue (random coil structure) and at 1645-1635 $\mathrm{cm}^{-1}$ is the imide residue of the typical $\beta$-sheet structure of gelatin. The gelatin FTIR was also a typical gelatin absorption peak in the amide II curve at $1560-1335 \mathrm{~cm}^{-1}$.

The vibration of amide II is due to the deformation of the $\mathrm{N}-\mathrm{H}$ bond. This absorption area is related to the deformation of tropocollagen into an $\alpha$-helix chain. The last specific absorption area of gelatin is amide III at $1300-1200 \mathrm{~cm}^{-1}$, which corresponds to N-H (Puspawati et al., 2012).

pH test

The $\mathrm{pH}$ values obtained from the three porcine gelatin samples were $5.23,5.35$, and 5.22 , within the range of 3.8-5.5 specified for gelatin type A according to GMIA (Table 1)

\section{Water content}

Water content will affect quality under storage because gelatin is a water-soluble hydrocolloid compound and can absorb water in considerable amounts. The samples met the GMIA requirements of $8-13 \%$ water (Table 2)

\section{Ash content}

The ash content is indicative of mineral content. Minerals are removed during immersion of the skin sample in an acid solution for $24 \mathrm{~h}$. The ash content meets the GMIA requirements of $0.3-2 \%$ (Table 3 ).

\section{Viscosity test}

According to GMIA standards (2012), gelatin viscosity should be in the range 15-75 mps. The sample viscosity did not meet this standard; however, the Ostwald viscometer has not been validated, and the rainfall test was not conducted (Table 4).

Table 1: Porcine skin gelatin $\mathrm{pH}$ versus standard

\begin{tabular}{llll}
\hline Substance & $\mathbf{p H}$ & $\mathbf{p H}$ mean & Standard deviation \\
\hline Gelatin standard & & & \\
1 & 5.11 & 5.14 & 0.03 \\
2 & 5.17 & & \\
3 & 5.13 & & \\
Sample gelatin & & & 0.07 \\
1 & 5.23 & 5.27 & \\
2 & 5.35 & & \\
3 & 5.22 & & \\
\hline
\end{tabular}

\section{Determination of amino acid retention time}

The order of retention times was hydroxyproline $<$ glycine $<$ proline using acetate: acetonitrile as the mobile phase because of the greater polarity of hydroxyproline compared to glycine and proline and the greater polarity of glycine compared to proline. For instance, under the optimized conditions, the retention times were 4.285, 6.050 and 10.874 min for hydroxyproline, glycine and proline, respectively.

\section{Determination of optimal hydrolysis time}

Gelatin samples were subjected to acid hydrolysis to break the peptide bonds and form peptides amenable to amino acid derivatization and analyzed using HPLC with fluorescence detection. For optimization, the optimal scan rate was compared among $10 \mu \mathrm{g} / \mathrm{mL}$ gelatin samples hydrolyzed for 22, 23, or $24 \mathrm{~h}$ (Table 5). On the basis of the results, $22 \mathrm{~h}$ was chosen as the hydrolysis time for all subsequent analyses.

\section{Determination of wavelength length analysis}

Selection of optimum detection wavelengths is critical for sensitivity and selectivity. The optimum analysis wavelengths for porcine gelatin were $265 \mathrm{~nm}$ for excitation and $320 \mathrm{~nm}$ for emission

\section{Optimum mobile phase composition}

The optimum mobile phase composition was determined by comparing analysis parameters ( $R$, peak sharpness, Tf, retention time, $N$, and HETP) among HPLC trials using acetate: acetonitrile ratios of 55:45, $60: 40$, and $65: 35$ at a flow rate of $0.8 \mathrm{~mL} / \mathrm{min}$. The $55: 45$ ratio was selected for subsequent analyses because it resulted in well separated but relatively short retention times and yielded better $\mathrm{N}$ and HETP than 60:40 and 65:35.

\section{Optimum flow rate}

In this study, $0.8 \mathrm{~mL} / \mathrm{min}$ was chosen as it yielded better $\mathrm{N}$ and HETP than 1.0 or $1.2 \mathrm{~mL} / \mathrm{min}$. Although the analysis time was longer at $0.8 \mathrm{~mL} / \mathrm{min}$, the difference was not significant compared to 1.0 and $1.2 \mathrm{~mL} / \mathrm{min}$. A flow rate of $0.8 \mathrm{~mL} / \mathrm{min}$ also resulted in better separation than 1 or $1.2 \mathrm{~mL} / \mathrm{min}$.

\section{Test system compatibility}

The HPLC system with optimal detection wavelengths, mobile phase composition, and flow rate met the repeatability requirement of coefficient of variation $\geq 2 \%$. In addition, the number of theoretical plates was >2500, and HETP was close to 0 (Tables 6-8)

\section{Preparation of the calibration curve and linearity test}

The calibration curves for hydroxyproline, glycine, and proline were constructed using $1,2,4,5,10$, and $20 \mathrm{~g} / \mathrm{mL}$ standard solutions of each amino acid derivatized with FMOC-Cl (Tables 9-11). The HPLC conditions were optimized as described. All three amino acids showed high linearity within the tested range as measured by the correlation coefficient (r) (hydroxyproline: $\mathrm{r}=0.9981$; glycine: $\mathrm{r}=0.9979$; proline: $\mathrm{r}=0.9985$ )

Table 2: Porcine skin gelatin water content

\begin{tabular}{llllllll}
\hline Sample & EBW $(\mathbf{g})$ & SW $(\mathbf{g})$ & EBW+BS $\mathbf{( g )}$ & SWAD $\mathbf{( g )}$ & KA & \%KA & Mean \\
\hline I & 20.828 & 1.0057 & 21.8337 & 21.7981 & 0.0356 & 3.56 & 3.52 \\
II & 21.231 & 1.0036 & 21.2346 & 21.1998 & 0.0348 & 3.48 & \\
\hline
\end{tabular}

EBW: Empty bottle weight, SW: Sample weight, SWAD: Sample weight after drying

Table 3: Porcine skin gelatin sample ash content

\begin{tabular}{lllllll}
\hline Sample & EPCW (g) & SW (g) & EPCW+SW (g) & SWAD (g) & KA & \%KA \\
\hline I & 21.5626 & 1.0001 & 22.5627 & 22.5598 & 0.0029 \\
II & 23.0650 & 1.0003 & 24.0653 & 24.0617 & 0.150 & 0.0036 \\
\hline
\end{tabular}

EPCW: Empty porcelain cup weight, SW: Sample weight, SWAD: Sample weight after drying 
Table 4: Porcine skin gelatin viscosity

\begin{tabular}{llll}
\hline Sample & Result (mps) & Mean & Method \\
\hline Porcine gelatin & 12.101 & 12.117 & Ostwald viscometer \\
& 12.143 & & \\
& 12.106 & & \\
\hline
\end{tabular}

Table 5: Relationship between hydrolysis time and scan rate optimum for derivatized amino acids in porcine skin gelatin

\begin{tabular}{llll}
\hline \multirow{2}{*}{ Time (h) } & \multicolumn{2}{l}{ Scan rate optimum $(\mathbf{m V} / \mathbf{s})$} \\
\cline { 2 - 4 } & Hydroxyproline & Glycine & Proline \\
\hline 22 & 473,505 & $2,873,869$ & $1,280,104$ \\
23 & 221,330 & 234,392 & 245,255 \\
24 & 124,358 & 22,014 & 245,255 \\
\hline
\end{tabular}

\section{Determination of $L O D$ and $L O Q$}

On the basis of the calibration curves, LOD was around $1 \mathrm{~g} / \mathrm{mL}$, and LOQ was approximately $3 \mathrm{~g} / \mathrm{mL}$ for all three amino acids (Tables 9-11).

\section{Determination of levels}

The amino acid levels in the isolated porcine gelatin were calculated using the linear regression equation. The average hydroxyproline level was $12.88 \pm 0.74 \%$; glycine, $28.57 \pm 0.48 \%$; and proline, $19.24 \pm 0.33 \%$ (Tables 12-14).

\section{CONCLUSION}

Our acid extraction method for porcine skin gelatin was $8.99 \%$ efficient. The purity of porcine gelatin was confirmed by functional group analysis using FTIR. The optimum conditions for the quantitation of hydroxyproline, glycine, and proline in porcine

Table 6: Comparison of HPLC system performances using different mobile phase compositions

\begin{tabular}{|c|c|c|c|c|c|c|c|c|c|c|c|c|c|c|c|}
\hline \multirow[t]{2}{*}{$\begin{array}{l}\text { Mobile phase } \\
\text { composition* }\end{array}$} & \multicolumn{3}{|c|}{ Retention time (min) } & \multicolumn{3}{|l|}{ Tf } & \multicolumn{3}{|l|}{ HETP } & \multicolumn{3}{|c|}{ Resolution } & \multicolumn{3}{|c|}{$\begin{array}{l}\text { Theoretical plate } \\
\text { number (N) }\end{array}$} \\
\hline & $\mathbf{A}$ & B & C & $\mathbf{A}$ & B & C & A & B & C & A & B & C & $\mathbf{A}$ & B & C \\
\hline $\begin{array}{l}\text { Acetate: } \\
\text { acetonitrile }(55: 45)\end{array}$ & 4.482 & 6.339 & 10.221 & 0.848 & 0.947 & 0.916 & 0.0084 & 0.0082 & 0.0079 & 2.984 & 4.059 & 8.012 & 19,010 & 30,339 & 31,68 \\
\hline $\begin{array}{l}\text { Acetate: } \\
\text { acetonitrile }(60: 40)\end{array}$ & 4.626 & 7.058 & 10.856 & 2.039 & 2.047 & 1.551 & 0.0336 & 0.0258 & 0.0055 & 3.824 & 2.365 & 3.196 & 7362 & 9692 & 4566 \\
\hline $\begin{array}{l}\text { Acetate: } \\
\text { acetonitrile }(65: 35)\end{array}$ & 6.161 & 7.205 & 11.673 & 1.339 & 0.865 & 0.954 & 0.1231 & 0.18155 & 0.0567 & 4.981 & 1.578 & 6.038 & 2031 & 1377 & 4407 \\
\hline
\end{tabular}

Table 7: Comparison of HPLC system performances at different mobile phase flow rates

\begin{tabular}{|c|c|c|c|c|c|c|c|c|c|c|c|c|c|c|c|}
\hline \multirow[t]{2}{*}{ Flow rate $(\mathrm{mL} / \mathrm{min})$} & \multicolumn{3}{|c|}{ Retention time (min) } & \multicolumn{3}{|l|}{ Tf } & \multicolumn{3}{|l|}{ HETP } & \multicolumn{3}{|c|}{ Resolution } & \multicolumn{3}{|c|}{$\begin{array}{l}\text { Theoretical plate } \\
\text { number (N) }\end{array}$} \\
\hline & $\mathbf{A}$ & B & C & $\mathbf{A}$ & B & C & A & B & C & $\mathbf{A}$ & B & C & $\mathbf{A}$ & B & C \\
\hline 0.8 & 4.482 & 6.339 & 10.221 & 0.848 & 0.947 & 0.916 & 0.0119 & 0.0082 & 0.0079 & 2.984 & 4.059 & 8.012 & 20,941 & 30,339 & 31,686 \\
\hline 1 & 4.411 & 6.425 & 9.541 & 1.113 & 0.986 & 1.95 & 0.0128 & 0.0128 & 0.0102 & 6.002 & 5.1 & 7.301 & 19,010 & 19,508 & 24,437 \\
\hline 1.2 & 3.795 & 5.566 & 9.143 & 0.873 & 0.905 & 0.816 & 0.0297 & 0.0181 & 0.0181 & 5.627 & 3.752 & 5.002 & 15,251 & 8414 & 13,811 \\
\hline
\end{tabular}

Table 8: Compliance test results for $10 \mu \mathrm{g} / \mathrm{mL}$ hydroxyproline

\begin{tabular}{llllllll}
\hline $\begin{array}{l}\text { Scan rate } \\
\text { optimum (mV/s) }\end{array}$ & $\begin{array}{l}\text { Retention } \\
\text { time (min) }\end{array}$ & Tf & HETP & $\begin{array}{l}\text { Theoretical plate } \\
\text { number (N) }\end{array}$ & Resolution & $\begin{array}{l}\text { Standard } \\
\text { deviation }\end{array}$ & $\begin{array}{l}\text { Coefficient of } \\
\text { variation }(\% C V)\end{array}$ \\
\hline 51,598 & 4.774 & 0.778 & 0.0488 & 5127 & 2.839 & 467.67 & 0.921 \\
50,345 & 4.767 & & & & & & \\
51,020 & 4.777 & & & & & & \\
50,751 & 4.769 & & & & & & \\
50,421 & 4.774 & & & & & & \\
50,561 & 4.779 & & & & & & \\
\hline
\end{tabular}

Calibration curve construction, linearity testing, and determination of LOD and LOQ. \%CV: Coefficient of variation, LOD: Limit of detection, LOQ: Limit of quantitation, Tf: Tailing factor, HETP: Height equivalent to the theoretical plate

Table 9: Hydroxyproline calibration curve, LOD, and LOQ under optimized HPLC conditions

\begin{tabular}{|c|c|c|c|c|c|c|c|}
\hline Concentration $(\mu \mathrm{g} / \mathrm{mL})$ & Scan rate optimum $(\mathrm{mV} / \mathrm{s})$ & $y i=a+b x$ & (y-yi) 2 & $S(y / x) 2$ & $S(y / x)$ & $\operatorname{LOD}(\mu \mathrm{g} / \mathrm{mL})$ & $\mathrm{LOQ}(\mu \mathrm{g} / \mathrm{mL})$ \\
\hline 1 & 28,552 & $28,635.4$ & 6955.56 & $246,748.641$ & 496.738 & 0.900 & 3.001 \\
\hline 2 & 30,100 & $30,920.8$ & $673,712.6$ & & & & \\
\hline 4 & 33,143 & $33,601.6$ & 210,314 & & & & \\
\hline 5 & 35,132 & 35,257 & 15,625 & & & & \\
\hline 10 & 44,957 & 43,534 & $2,024,929$ & & & & \\
\hline 20 & 59523 & 60,088 & 319,225 & & & & \\
\hline
\end{tabular}


Table 10: Glycine calibration curve, LOD, and LOQ under optimized HPLC conditions

\begin{tabular}{|c|c|c|c|c|c|c|c|}
\hline Concentration $(\mu \mathrm{g} / \mathrm{mL})$ & Scan rate optimum (mV/s) & $y i=a+b x$ & $(y-y i) 2$ & $S(y / x) 2$ & $S(y / x)$ & LOD $(\mu \mathrm{g} / \mathrm{mL})$ & LOQ $(\mu \mathrm{g} / \mathrm{mL})$ \\
\hline 1 & 44,627 & $39,782.2$ & $23,472,087$ & $9,531,137.261$ & 3087.254 & 0.990 & 3.301 \\
\hline 2 & 51,107 & $49,133.4$ & $3,895,097$ & & & & \\
\hline 4 & 61,971 & $67,835.8$ & $34,395,879$ & & & & \\
\hline 5 & 72,445 & 77,187 & $22,486,564$ & & & & \\
\hline 10 & 127,680 & 123,948 & $13,927,824$ & & & & \\
\hline 20 & 217,504 & 217,455 & 2401 & & & & \\
\hline
\end{tabular}

LOD: Limit of detection, LOQ: Limit of quantitation, HPLC: High-performance liquid chromatography

Table 11: Proline calibration curve, LOD, and LOQ under optimized HPLC conditions

\begin{tabular}{|c|c|c|c|c|c|c|c|}
\hline Concentration $(\mu \mathrm{g} / \mathrm{mL})$ & Scan rate optimum $(\mathrm{mV} / \mathrm{s})$ & $y i=a+b x$ & $(y-y i) 2$ & $S(y / x) 2$ & $S(y / x)$ & LOD $(\mu \mathrm{g} / \mathrm{mL})$ & LOQ $(\mu \mathrm{g} / \mathrm{mL})$ \\
\hline 1 & 41,472 & $44,683.4$ & $10,313,090$ & $3,754,169.755$ & 1937.568 & 0.998 & 3.327 \\
\hline 2 & 53,543 & $50,507.8$ & $9,212,439$ & & & & \\
\hline 4 & 61,478 & $62,156.6$ & 460,498 & & & & \\
\hline 5 & 67,696 & 67,981 & 81,225 & & & & \\
\hline 10 & 99,256 & 97,103 & $4,635,409$ & & & & \\
\hline 20 & 154,334 & 155,347 & $1,026,169$ & & & & \\
\hline
\end{tabular}

LOD: Limit of detection, LOQ: Limit of quantitation, HPLC: High-performance liquid chromatography

Table 12: Hydroxyproline levels in cured porcine skin gelatin samples

\begin{tabular}{lllll}
\hline Gelatin concentration $(\boldsymbol{\mu g} / \mathbf{m L})$ & Scan rate optimum $(\mathbf{m V} / \mathbf{s})$ & Glycine level $(\boldsymbol{\mu g} / \mathbf{m L})$ & Level $(\%)$ & Mean \pm standard deviation $(\%)$ \\
\hline 10 & 57,651 & 2.9109 & 29.109 & $28.571 \pm 0.48$ \\
& 56,781 & 2.8178 & 28.178 & \\
\hline
\end{tabular}

Table 13: Glycine levels in cured porcine skin gelatin samples

\begin{tabular}{lllll}
\hline Gelatin concentration $(\boldsymbol{\mu g} / \mathbf{m l})$ & Scan rate optimum $(\mathbf{m V} / \mathbf{s})$ & Glycine level $(\boldsymbol{\mu g} / \mathbf{m l})$ & Level $(\%)$ & Mean \pm standard deviation $(\%)$ \\
\hline 10 & 57,651 & 2.9109 & 29.109 & $28.571 \pm 0.48$ \\
& 56,781 & 2.8178 & 28.178 & \\
\hline
\end{tabular}

Table 14: Proline levels in cured porcine skin gelatin samples

\begin{tabular}{lllll}
\hline Gelatin concentration $(\boldsymbol{\mu g} / \mathbf{m L})$ & Scan rate optimum $(\mathbf{m V} / \mathbf{s})$ & Proline level $(\boldsymbol{\mu g} / \mathbf{m L})$ & Level $(\%)$ & Mean \pm standard deviation $(\%)$ \\
\hline 10 & 50,231 & 1.9525 & 19.525 & $19.236 \pm 0.33$ \\
& 49,856 & 1.8881 & 18.881 & \\
\hline
\end{tabular}

gelatin using HPLC with fluorescence detection were as follows: Excitation wavelength of $265 \mathrm{~nm}$, emission wavelength of $320 \mathrm{~nm}$, YMC-Triart ${ }^{\circledR}$ C18 column $(250 \mathrm{~mm}, 4.6 \mathrm{~mm}$ inner diameter size, and $5 \mu \mathrm{m}$ particle size), acetic acid: acetonitrile of $55: 45(\mathrm{v} / \mathrm{v})$ as the mobile phase, and flow rate of $0.8 \mathrm{~mL} / \mathrm{min}$. The optimum condition for the hydrolysis of porcine gelatin before fluorophore tagging was heating in HCL for $22 \mathrm{~h}$ at $110^{\circ} \mathrm{C}$. The LOD and LOQ were approximately 1 and $3 \mathrm{~g} / \mathrm{mL}$, respectively. The mean hydroxyproline, glycine, and proline fractions in porcine gelatin samples were $12.88 \pm 0.74 \%, 28.57 \pm 0.48 \%$, and $19.24 \pm 0.33 \%$, respectively. This acid extraction and HPLC-based quantitation method allow for rapid, sensitive, and accurate measures of gelatin purity and amino acid composition.

\section{CONFLICTS OF INTEREST}

All authors have none to declare.

\section{REFERENCES}

1. Damanik A. Halal Gelatin and Non-halal Gelatin. Jakarta: Jurnal Halal LPPOM MUI No. 36; 2001.

2. Schrieber R, Gareis H. Gelatin Handbook: Theory and Industrial
Practice. Weinheim: Wiley-VCH Verlag Gmbh; 2007.

3. Gelatin Manufacturer's Institute of America. Standard Methods for the Testing of Edible Gelatin. America: Gelatin Manufacturers Institute of America, Inc.; 2012.

4. Azilawati MI, Hashim DM, Jamilah B, Amin I. Validation of a reverse-phase high-performance liquid chromatography method for the determination of amino acids in gelatins by application of 6-aminoquinolyl-N-hydroxysuccinimidyl carbamate reagent. J Chromatogr A 2014;1353:49-56.

5. Azilawati MI, Hashim DM, Jamilah B, Amin I. RP-HPLC method using 6-aminoquinolyl-N-hydroxysuccinimidyl carbamate incorporated with normalization technique in principal component analysis to differentiate the bovine, porcine and fish gelatins. Food Chem 2015;172: 368-76.

6. Fabiani A, Versari A, Parpinello GP, Castellari M, Galassi S. Highperformance liquid chromatographic analysis of free amino acids in fruit juices using derivatization with 9-fluorenylmethyl-chloroformate. J Chromatogr Sci 2002;40:14-8.

7. Coppex L. Derivatives for HPLC Analysis. Jerman: Faculty of Chemistry and Pharmacy University of Genf; 2000.

8. Fakhri S, Mohammadi B, Jalili R, Hajialyani M, Bahrami G. Screening and confirmation of different synthetic adulterants in slimming products. Asian J Pharm Clin Res 2018;11:260-4.

9. Ahda M, Guntarti A, Kusbandari A. Application of high-pressure 
liquid chromatography for analysis of lard in the meatball product combined with principal component analysis. Asian J Pharm Clin Res 2016;9:120-3.

10. Bakar RA, Miran H. Validated high performance liquid chromatography (HPLC) method for analysis of methamphetamine in human urine using liquid-liquid extraction. Asian J Pharm Clin Res 2015;8:199-201.

11. Sompie M, Surtijono SE, Pontoh JH, Lontaan NN. The effects of acetic acid concentration and extraction temperature on physical and chemical properties of porcine skin gelatin. First Int Symp Food Agro Biodivers $2015 ; 3: 383-8$ 